\title{
OPTIMASI PANJANG CADIK KAPAL NELAYAN 3 GT
}

\author{
Budhi Santoso $^{1}$, Muhammad Helmi ${ }^{2}$, Nurhasanah $^{3}$ \\ 1,2,3 Jurusan Teknik Perkapalan Politeknik Negeri Bengkalis \\ Jl. Bathin Alam, Sungai Alam, Bengkalis-Riau, 28761 \\ Email: budhynaval@gmail.com
}

\begin{abstract}
Increased speed on fishing vessels will assist in the operation of fishing in the sea. Some research has a lot of speed improvement by adding starboard port side hull. The value of total resistance to variations in distance outrigger vessel (outrigger) on speed 10 knots generate resistance values at a distance outrigger 2 meters of $10.6 \mathrm{kN}$, outrigger distance of 2.5 meters of $10.7 \mathrm{kN}$, while at a distance of 3 meters outrigger 10, $8 \mathrm{kN}$. Thus, variations distance outrigger are not significant influence total resistance value of the vessel 3 $G T$, in because the resistance value is not much different.
\end{abstract}

Keywords: outrigger, resistance, fishing ship, speed

\begin{abstract}
ABSTRAK
Peningkatan kecepatan pada kapal nelayan akan membantu dalam operasional penangkapan ikan di laut. Beberapa penelitian telah dilakukan tentang peningkatan kecepatan dengan menambah lambung di kanan-kiri kapal. Nilai hambatan total kapal terhadap variasi jarak outrigger (cadik) pada kecepatan kapal 10 knot menghasilkan nilai hambatan pada jarak cadik 2 meter 10,6 kN, jarak cadik 2,5 meter 10,7 kN, sedangkan pada jarak cadik 3 meter $10,8 \mathrm{kN}$. Dengan demikian, variasi jarak cadik tidak signifikan mempengaruhui nilai hambatan total kapal 3 GT dikarenakan nilai hambatan tidak jauh berbeda.
\end{abstract}

Kata kunci: cadik, hambatan, kapal ikan, kecepatan

\section{PENDAHULUAN}

Penangkapan ikan dengan alat tangkap jaring yang digunakan oleh para nelayan skala kecil dengan mengunakan armada alat tangkap berukuran 1 GT sampai 3 GT di kabupaten Bengkalis membutuhkan stabilitas kapal yang baik. Desain kapal tradisional yang digunakan di pesisir pantai kabupaten Bengkalis mengunakan satu lambung [1]. Dengan adanya outrigger (cadik), bentuk lambung kapal menjadi tiga bagian atau sering disebut trimaran. Pengembangan bentuk kapal dari lambung tunggal menjadi trimaran bertujuan untuk meningkatkan kestabilan kapal dan kecepatan kapal pada saat beroperasi. Penelitian yang telah dilakukan membuktikan bahwa bentuk lambung trimaran memiliki hambatan yang lebih kecil dibandingkan dengan lambung kapal tunggal [2]. Penambahan cadik di kanan-kiri kapal akan menambah kestabilan kapal pada saat operasi [3].

Berbagai teknologi terus dikembangkan untuk mendapatkan bentuk lambung kapal yang sesuai dengan kebutuhan manusia yang semakin beragam, dalam hal ini ditekankan pada efisiensi energi. Salah satu cara mencapai tujuan tersebut adalah dengan mengoptimalkan jarak cadik terhadap lambung kapal. Dengan begitu, dapat diketahui seberapa pengaruhnya terhadap hambatan kapal akibat jarak cadik.

\section{TINJAUAN PUSTAKA}

Kapal terbagi menjadi dua daerah utama dilihat berdasarkan bagian atas air dan bagian bawah air. Bagian bawah air yang tercelup air menimbulkan gaya yang berlawanan dengan arah gerak badan kapal. Nilai gaya berlawanan itu harus dibuat seminimal mungkin karena berkaitan daya mesin utama kapal yang digunakan oleh kapal untuk melawan gaya tersebut sehingga mampu mendorong kapal berjalan. 
Tahanan total kapal dapat diperoleh melalui beberapa cara, yaitu perhitungan secara analitis (teoritis), pengujian model fisik di tangki percobaan (eksperimen), atau dengan pensimulasian model kapal di komputer (numerik). Perhitungan secara analitis memberikan bentuk persamaan matematis, tetapi semua kejadian dapat dituangkan dalam bentuk matematis. Percobaan dapat memberikan hasil yang praktis dan memiliki tingkat keakurasian tinggi. Kekurangannya, teknik ini membutuhkan biaya pembangunan fasilitas percobaan yang tinggi. Sedangkan simulasi model kapal di komputer dapat memberikan hasil yang mendekati dengan keadaan yang sebenarnya. Keuntungannya, teknik ini tidak membutuhkan waktu yang lama dan biaya yang jauh lebih kecil dibandingkan melakukan ekperimen, tetapi sulit dalam melakukan validasi [4].

Secara manual dan sederhana, tahanan total kapal, $R_{T}$, dapat diperoleh dengan cara menjumlahkan semua komponen-komponen tahanan yang bekerja pada kapal, yang meliputi tahanan gesek (friction resistance, $R_{F}$ ), tahanan gelombang (wave resistance, $R_{W}$ ), tahanan udara (air resitance, $R_{A}$ ), dan lain-lain [4], umumnya diformulasikan dengan persamaan:

$$
R_{T}=0,5 \times \rho \times C_{T} \times S \times V^{2} S
$$

dengan $\rho$ adalah massa jenis fluida $\left(1.025 \mathrm{~kg} / \mathrm{m}^{3}\right)$

$V s$ adalah kecepatan kapal $(\mathrm{m} / \mathrm{s})$

$C_{T}$ adalah koefisien tahanan total kapal

$S$ adalah luasan permukaan basah dari badan kapal $\left(\mathrm{m}^{2}\right)$

Maxsurf dan Hullspeed, kedua produk tersebut merupakan software dari Formation Design System Pty. Ltd. Maxsurf adalah suatu sistem pemodelan berbasis surface 3-D (three-dimensional surface modelling system) yang sangat handal untuk penggunaan di bidang marine design. Maxsurf memiliki kemampuan multiple surface yang memungkinkan sejumlah permukaan dapat digunakan untuk memodelkan berbagai macam desain untuk lambung kapal. Surface dalam Maxsurf didefinisikan sebagai posisi dari satu set control point untuk digeser, membuat surface yang dibuat dapat dimanipulasi menjadi bentuk yang diinginkan. Program Hullspeed merupakan sistem pendukung Maxsurf yang memiliki kemampuan untuk mengestimasi tahanan kapal dan daya main engine dari badan kapal yang telah didesain dalam Maxsurf.

\section{METODE}

\section{Redrawing Kapal}

Dalam penyusunan analisis pada kapal nelayan 3 GT ini digunakan tahapan-tahapan metode dalam melakukan penelitian sebagai berikut.

\section{Pengukuran Data Utama Kapal}

Pengukuran kapal dilakukan pada kapal nelayan di daerah kabupaten Bengkalis Riau. Kapal yang diambil adalah kapal 3 GT. Pengukuran dilakukan secara langsung di lokasi dengan menggunakan peralatan ukur. Adapun detail data ukurnya sebagaimana berikut.

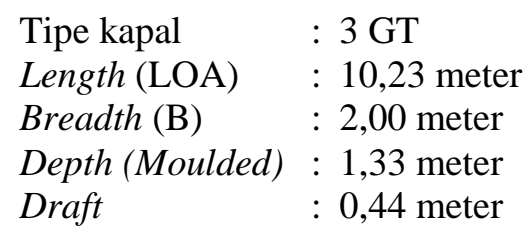

\section{Perhitungan Hambatan Kapal}

Perhitungan hambatan kapal menggunakan metode numerik yang dibantu perangkat lunak. Pemilihan metode perhitungan hambatan kapal dilakukan dengan kriteria sebagai berikut [5].

1. Savitsky pre-planning: Metode perhitungan hambatan kapal untuk kapal cepat planning hull pada kondisi sebelum planning (pre-planning).

2. Savitsky planning: Metode perhitungan hambatan kapal untuk kapal cepat planning hull yang bekerja pada kondisi planning (kecepatan planning). 
3. Lahtiharju: Metode perhitungan hambatan kapal untuk kapal cepat planning hull pada kondisi planning (kecepatan planning).

4. Holtrop: Metode perhitungan hambatan kapal untuk kapal tanker, kapal kargo, kapal ikan, tug boat, kapal kontainer, dan kapal frigate.

5. Van Ootmerssen: Metode perhitungan hambatan kapal untuk kapal-kapal kecil misalnya kapal ikan dan kapal tug boat.

6. Series 60: Metode perhitungan hambatan kapal untuk kapal kargo dengan satu propeller (single screw propeller).

7. Delf Series: Metode perhitungan hambatan kapal untuk kapal layar (sailing yacht) berdasarkan metode perhitungan regresi.

8. Metode Harvard: Metode perhitungan tahanan kapal berdasarkan bentuk lambung kapal secara manual yang terkait, berupa tahana bentuk lambung bawah air, tahanan udara, dan tahanan tambahan.

Dengan bantuan perangkat lunak, data utama kapal dimasukkan sebagai input. Metode yang digunakan dalam perhitungan hambatan kapal menggunakan Van Ootmerssen. Metode yang digunakan adalah Van Oortmeersen karena Van Oortmeersen mengakomodasi jenis kapal ikan yang salah satunya berjenis kapal penangkap ikan. Kecepatan kapal rata-rata 10 knot merupakan kecepatan servis pada saat mode berlayar dari fishingbase menuju fishingground (selling). Tahanan yang diterima kapal jarak cadik 2 meter adalah 30,2 kN; kapal dengan cadik 2,5 meter adalah 36,5 $\mathrm{kN}$; kapal dengan cadik 3 meter adalah 43,6 kN. Selanjutnya, dilakukan variasi jarak cadik terhadap badan kapal dengan jarak $2 \mathrm{~m}$ dari center line; $2,5 \mathrm{~m}$ dari center line; dan $3 \mathrm{~m}$ dari center line. Tahanan kapal diperoleh dari perhitungan hull speed dan hitungan manual. Jarak cadik tersebut mengahasilkan perbandingan S/L sebesar 0,19;0,24; dan 0,29. Perbandingan tersebut dapat dilihat pada Gambar 1, Gambar 2, dan Gambar 3 berikut.

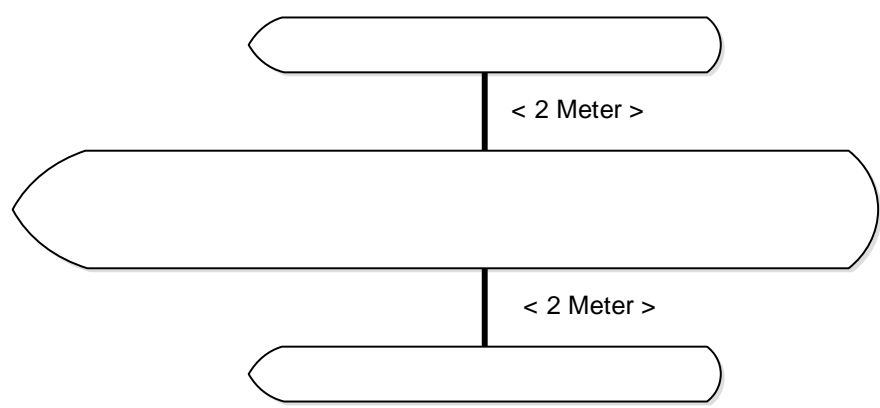

Gambar 1. Jarak cadik 2 meter

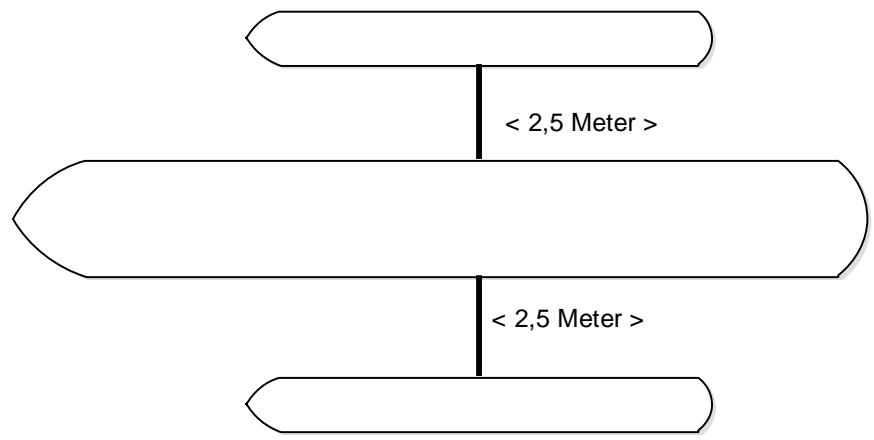

Gambar 2. Jarak cadik 2,5 meter 


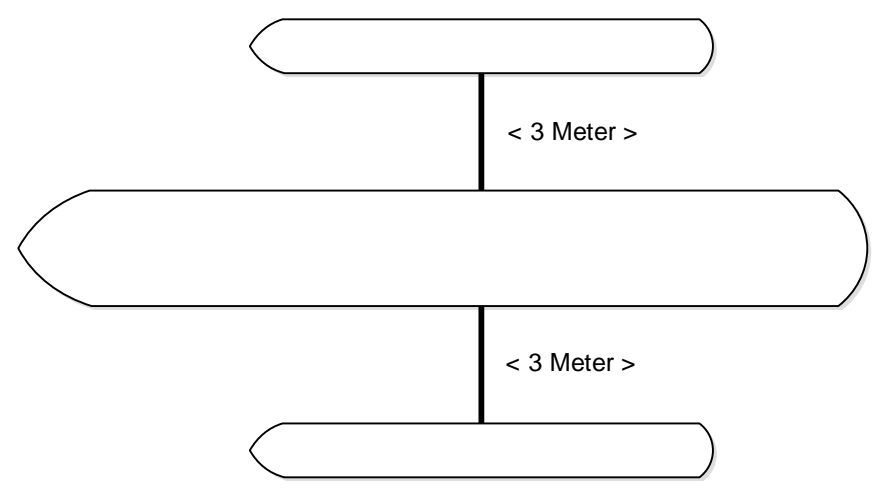

Gambar 3. Jarak cadik 3 meter

Hambatan kapal adalah gerakan fluida yang berlawan arah dengan arah gerakan kapal yang memiliki kecepatan tertentu sehingga akan menimbulkan gaya fluida yang berlawanan dengan gaya kapal [6]. Hambatan total kapal terdiri atas hambatan viscous $(R v)$ dan hambatan gelombang $(R w)$. Hambatan viscous terbentuk karena adanya hambatan gesek dan faktor bentuk dari badan kapal.

Untuk menganalisis dan menentukan tahanan kapal digunakan metode Van Ootmersent. Metode tersebut cukup sesuai untuk dipilih karena kapal ikan tradisional umumnya memiliki ukuran kecil [7]. Kemudian, dilakukan analisa hambatan pada tiap-tiap jarak cadik.

\section{HASIL DAN PEMBAHASAN}

Hasil analisis berupa nilai hambatan kapal masing-masing variasi jarak cadik secara keseluruhan. Terdapat beberapa komponen hambatan kapal yang menjadi dasar hasil perhitungan hambatan total kapal nelayan 3 GT. Komponen yang dominan dalam mendapatkan hambatan total adalah hambatan viscous. Hambatan kapal dengan metode Van Oortmerssen bersifat tidak linier, dengan peningkatan kecepatan kapal, akan terjadi penurunan hambatan kapal.

Berdasarkan teori dasar hidrodinamika, hambatan total berbanding dengan nilai tegangan tangensial pada seluruh permukaan basah kapal, sehingga besar kecilnya nilai hambatan total kapal berbanding lurus dengan luasan badan kapal yang tercelup air. Semakin besar permukaan badan kapal yang tercelup air maka nilai hambatan juga semakin besar, begitu juga sebaliknya. Hal ini disebabkan sebagian besar fluida memiliki viskositas yang menimbulkan gesekan pada badan kapal. Pada Gambar 4 dapat dilihat bahwa hambatan total kapal tiga variasi jarak cadik dengan mengunakan metode Van Ootmersent meghasilkan nilai yang cukup baik. Meskipun hambatan kapal mengalami titik balik pada kecepatan lebih kurang $10 \mathrm{kN}$, namun kembali meningkat seiring dengan bertambahnya kecepatan kapal.

Variasi jarak cadik pada kapal nelayan 3 GT tidak memberikan pengaruh terhadap besarnya nilai hambatan total kapal, karena grafik berhimpit sehingga nilai hambatan kapal untuk setiap variasi jarak cadik relatif sama.

Tabel 1. Perhitungan tahanan total

\begin{tabular}{rrrrrrrr}
\hline $\begin{array}{r}\text { Speed } \\
(\mathrm{knot})\end{array}$ & \multicolumn{3}{c}{ Van Oot $(\mathrm{kN})$} & & Speed & \multicolumn{3}{c}{ Van Oot $(\mathrm{kN})$} \\
\cline { 6 - 7 }$(\mathrm{m})$ & $2.5 \mathrm{~m}$ & $3 \mathrm{~m}$ & & $2 \mathrm{~m}$ & $2.5 \mathrm{~m}$ & $3 \mathrm{~m}$ \\
\hline 0 & 0 & 0 & 0 & 5.625 & 0.9 & 0.9 & 0.9 \\
0.375 & 0 & 0 & 0 & 6 & 1 & 1 & 1.1 \\
0.75 & 0 & 0 & 0 & 6.375 & 1.2 & 1.2 & 1.2 \\
1.125 & 0 & 0 & 0 & 6.75 & 1.5 & 1.5 & 1.5 \\
1.5 & 0.1 & 0.1 & 0.1 & 7.125 & 2.1 & 2.1 & 2.1 \\
1.875 & 0.1 & 0.1 & 0.1 & 7.5 & 3.2 & 3.2 & 3.2 \\
2.25 & 0.2 & 0.2 & 0.2 & 7.875 & 4.5 & 4.5 & 4.6 \\
2.625 & 0.2 & 0.2 & 0.2 & 8.25 & 6 & 6 & 6.1 \\
3 & 0.3 & 0.3 & 0.3 & 8.625 & 7.3 & 7.4 & 7.5 \\
3.375 & 0.3 & 0.3 & 0.3 & 9 & 8.5 & 8.5 & 8.6 \\
3.75 & 0.4 & 0.4 & 0.4 & 9.375 & 9.4 & 9.5 & 9.6 \\
\hline
\end{tabular}




\begin{tabular}{|c|c|c|c|c|c|c|c|}
\hline \multirow{2}{*}{$\begin{array}{l}\text { Speed } \\
\text { (knot) }\end{array}$} & \multicolumn{3}{|c|}{ Van Oot $(\mathrm{kN})$} & \multirow{2}{*}{$\begin{array}{l}\text { Speed } \\
\text { (knot) }\end{array}$} & \multicolumn{3}{|c|}{ Van Oot $(\mathrm{kN})$} \\
\hline & $2 \mathrm{~m}$ & $2.5 \mathrm{~m}$ & $3 \mathrm{~m}$ & & $2 \mathrm{~m}$ & $2.5 \mathrm{~m}$ & $3 \mathrm{~m}$ \\
\hline 4.125 & 0.4 & 0.4 & 0.4 & 9.75 & 10.1 & 10.2 & 10.2 \\
\hline 4.5 & 0.5 & 0.5 & 0.5 & 10.125 & 10.6 & 10.7 & 10.8 \\
\hline 4.875 & 0.6 & 0.6 & 0.6 & 10.5 & 11.1 & 11.1 & 11.2 \\
\hline 5.25 & 0.7 & 0.7 & 0.7 & 10 & 11.5 & 11.5 & 11.6 \\
\hline
\end{tabular}

\section{Resistance-Speed Curve Total}

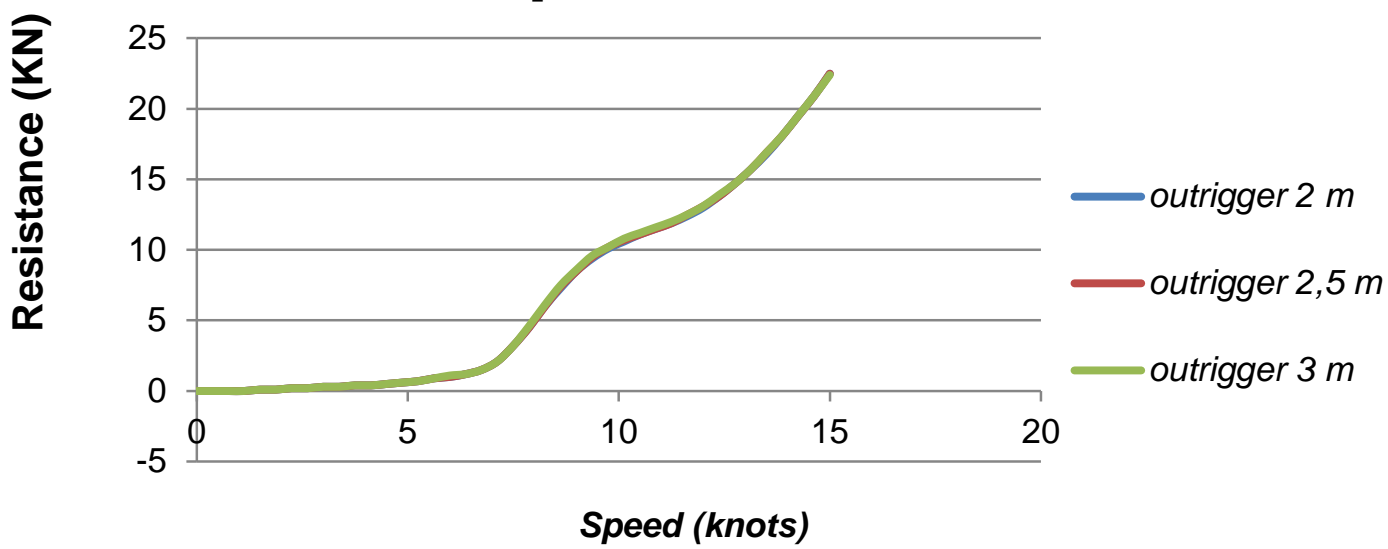

Gambar 4. Grafik hambatan total kapal semua variasi jarak cadik

Pada Gambar 5 dapat dilihat bahwa kenaikan nilai hambatan kapal untuk ketiga variasi jarak cadik tidak stabil pada froude number di bawah 1,5 dan stabil pada froude number di atas 1,5. Variasi jarak cadik pada kapal nelayan 3 GT tidak memberikan pengaruh terhadap terbentuknya hambatan gelombang kapal.

Tabel 2. Frounde Number

\begin{tabular}{|c|c|c|c|c|c|c|c|}
\hline \multirow{2}{*}{$\begin{array}{l}\text { Speed } \\
\text { (knot) }\end{array}$} & \multicolumn{3}{|c|}{$\mathrm{Fn}(\mathrm{kN})$} & \multirow{2}{*}{$\begin{array}{l}\text { Speed } \\
\text { (knot) }\end{array}$} & \multicolumn{3}{|c|}{ Fn } \\
\hline & $2 \mathrm{~m}$ & $2.5 \mathrm{~m}$ & $3 \mathrm{~m}$ & & $2 \mathrm{~m}$ & $2.5 \mathrm{~m}$ & $3 \mathrm{~m}$ \\
\hline 0 & 0 & 0 & 0 & 5.625 & 0.624 & 0.624 & 0.624 \\
\hline 0.375 & 0.042 & 0.042 & 0.042 & 6 & 0.666 & 0.666 & 0.666 \\
\hline 0.75 & 0.083 & 0.083 & 0.083 & 6.375 & 0.708 & 0.707 & 0.707 \\
\hline 1.125 & 0.125 & 0.125 & 0.125 & 6.75 & 0.749 & 0.749 & 0.749 \\
\hline 1.5 & 0.166 & 0.166 & 0.166 & 7.125 & 0.791 & 0.791 & 0.79 \\
\hline 1.875 & 0.208 & 0.208 & 0.208 & 7.5 & 0.832 & 0.832 & 0.832 \\
\hline 2.25 & 0.25 & 0.25 & 0.25 & 7.875 & 0.874 & 0.874 & 0.874 \\
\hline 2.625 & 0.291 & 0.291 & 0.291 & 8.25 & 0.916 & 0.916 & 0.915 \\
\hline 3 & 0.333 & 0.333 & 0.333 & 8.625 & 0.957 & 0.957 & 0.957 \\
\hline 3.375 & 0.375 & 0.375 & 0.374 & 9 & 0.999 & 0.999 & 0.998 \\
\hline 3.75 & 0.416 & 0.416 & 0.416 & 9.375 & 1.041 & 1.04 & 1.04 \\
\hline 4.125 & 0.458 & 0.458 & 0.458 & 9.75 & 1.082 & 1.082 & 1.082 \\
\hline 4.5 & 0.499 & 0.499 & 0.499 & 10.125 & 1.124 & 1.124 & 1.123 \\
\hline 4.875 & 0.541 & 0.541 & 0.541 & 10.5 & 1.165 & 1.165 & 1.165 \\
\hline 5.25 & 0.583 & 0.583 & 0.582 & 10 & 1.207 & 1.207 & 1.206 \\
\hline
\end{tabular}




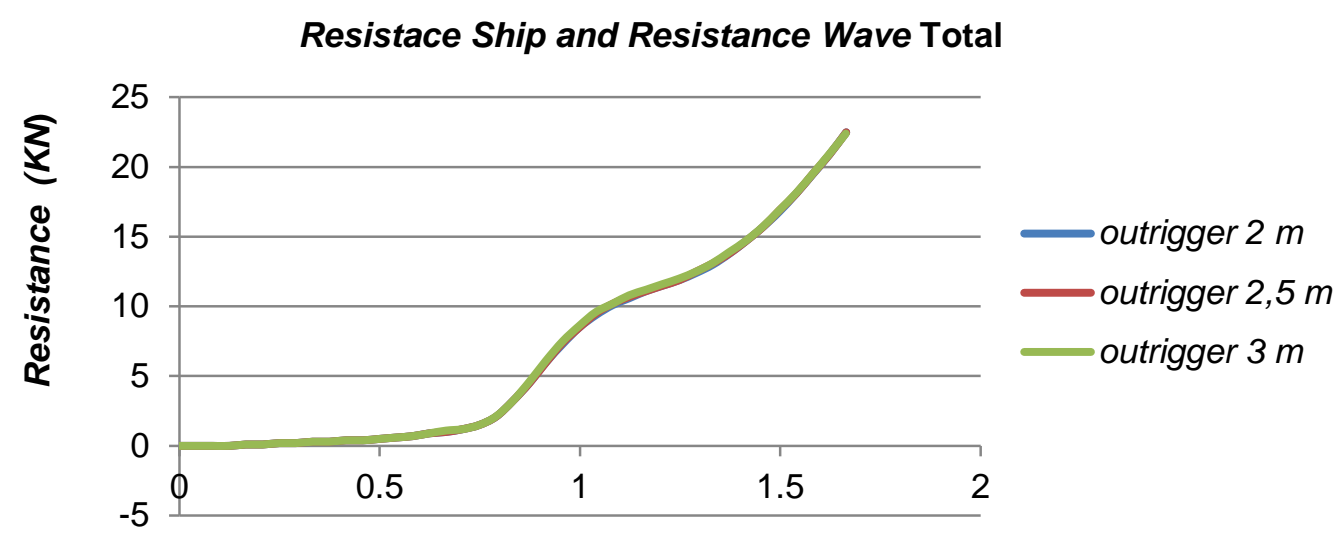

Froude Number

Gambar 5. Grafik hambatan kapal dengan hambatan gelombang semua variasi jarak cadik

\section{KESIMPULAN}

Pengaruh penambahan moveable cadik pada kapal nelayan 3 GT masyarakat nelayan terhadap hambatan total kapal memberikan nilai pada kecepaan kapal 10 knots jarak cadik 2 meter 10,6 kN; jarak cadik 2,5 meter $10,7 \mathrm{kN}$; jarak cadik 3 meter $10,8 \mathrm{kN}$. Variasi jarak cadik tidak memberikan pengaruh signifikan terhadap nilai hambatan total karena hasil perhitungan relatif sama. Kenaikan nilai hambatan kapal stabil pada froude number diatas 1,5. Dapat disimpulkan variasi jarak cadik sangat berpengaruh pada terbentuknya hambatan gelombang.

\section{DAFTAR PUSTAKA}

[1] Nurhasanah, 2014. Evaluasi karakteristik hidrodinamika kapal ikan untuk wilayah perairan pulau Bengkalis. Riau.

[2] S.A. Harvald, 1983. Tahanan dan Propulsi Kapal. Surabaya: Airlangga University Press.

[3] A.W. Gray, 2001. A Preliminary Study pf Trimaran. West Virginia University College of Engineering and Material Resources, Morgantown.

[4] Utama, I.K.A.P., 2008. Peranan Hidrodinamika dalam Bidang Desain Kapal dan Kehidupan Sehari-hari, Pidato Pengukuhan untuk Jabatan Guru Besar dalam Bidang Ilmu Hidrodinamika Kapal pada Fakultas Telnologi Kelautan Institut Teknologi Sepuluh Nopember Surabaya 4 Juni 2008, Departemen Pendidikan Nasional, Institut Teknologi Sepuluh Nopember, Surabaya.

[5] Muhadi Eko, 2012. Analisa Teknis Optimalisasi Sistem Propulsi Kapal Ikan Menggunakan Cvt Gearbox. KAPAL, 9(3), Surabaya.

[6] T. Mynard, PK. Sahoo, J. Mikkelsen and D. McGreer., 2008. Numerical and Experimantel Study of Wave Resistance for Trimaran Hull Form. Australian Maritime College, Lunceston, Australia.

[7] Oortmerssen, G., A Power Prediction Method and its Application to Small Ships. International Shipbuilding Progress, 18(207), 1971.

[8] Adji, Surjo W., 2004. Kapal Ikan Kajian Karakteristik Tahanan dan Sistem Propulsi, Modul Pengajaran, Jurusan Teknik Sistem Perkapalan FTK-ITS, Surabaya. 